\title{
Short-term volcano-tectonic earthquake forecasts based on a moving mean recurrence time algorithm: the EI Hierro seismo-volcanic crisis experience
}

\author{
Alicia García ${ }^{1}$, Servando De la Cruz-Reyna ${ }^{2,3}$, José M. Marrero ${ }^{4,5}$, and Ramón Ortiz ${ }^{1}$ \\ ${ }^{1}$ Institute IGEO, CSIC-UCM, J. Gutierrez Abascal, 2, Madrid 28006, Spain \\ ${ }^{2}$ Instituto de Geofísica, Universidad Nacional Autónoma de México, C. Universitaria, México D.F. 04510, México \\ ${ }^{3}$ CUEIV, Universidad de Colima, Colima 28045, México \\ ${ }^{4}$ Instituto Geofísico, Escuela Politécnica Nacional, Ladrón de Guevara, P.O. Box 1701-2759, Quito, Ecuador \\ ${ }^{5}$ Unidad de Gestión, Investigación y Desarrollo, Instituto Geográfico Militar, El Dorado, 170413, Quito, Ecuador
}

Correspondence to: Alicia García (alicia.g@igeo.ucm-csic.es)

Received: 3 October 2015 - Published in Nat. Hazards Earth Syst. Sci. Discuss.: 18 January 2016

Revised: 9 April 2016 - Accepted: 27 April 2016 - Published: 13 May 2016

\begin{abstract}
Under certain conditions, volcano-tectonic (VT) earthquakes may pose significant hazards to people living in or near active volcanic regions, especially on volcanic islands; however, hazard arising from VT activity caused by localized volcanic sources is rarely addressed in the literature. The evolution of VT earthquakes resulting from a magmatic intrusion shows some orderly behaviour that may allow the occurrence and magnitude of major events to be forecast. Thus governmental decision makers can be supplied with warnings of the increased probability of largermagnitude earthquakes on the short-term timescale. We present here a methodology for forecasting the occurrence of large-magnitude VT events during volcanic crises; it is based on a mean recurrence time (MRT) algorithm that translates the Gutenberg-Richter distribution parameter fluctuations into time windows of increased probability of a major VT earthquake. The MRT forecasting algorithm was developed after observing a repetitive pattern in the seismic swarm episodes occurring between July and November 2011 at El Hierro (Canary Islands). From then on, this methodology has been applied to the consecutive seismic crises registered at El Hierro, achieving a high success rate in the real-time forecasting, within 10-day time windows, of volcano-tectonic earthquakes
\end{abstract}

\section{Introduction}

Volcano-tectonic (VT) earthquakes are considered to be lowmagnitude compared to tectonic earthquakes, even though in some cases (three in the twentieth century) they have reached $M \geq 7$ (Zobin, 2001). Volcanic earthquakes occurring near active subduction zones, which may often reach magnitudes in the range 4-6, rarely cause the same degree of damage or concern among the population that stronger tectonic earthquakes cause. However, in volcanic regions with low tectonic activity, and consequently with a higher vulnerability to strong ground motions, events exceeding M4 may produce significant damage. Such a situation may become quite serious when that type of VT activity occurs in volcanic islands with unstable topographies, prone to landslides, as is the case of El Hierro, the westernmost, youngest ( $<2 \mathrm{Ma}$, Ancochea et al., 1994), and smallest $\left(269 \mathrm{~km}^{2}\right)$ of the Canary Islands.

In general, earthquake forecasting requires answers to four questions: where, when, how likely, and how large? In VT earthquake forecasting, the answer to where the earthquake is is constrained by the extent of the volcanic system. The answer to the second question on timing is related to the onset and evolution of a volcanic crisis. Such crises are generally characterized by VT seismic swarms, lasting an average of 5.5 days in the case of El Hierro, concentrated in regions within or around the volcanic system, and generally defined as "a sequence of events closely clustered in time and space" (Benoit and McNutt, 1996). Since such swarms may include 

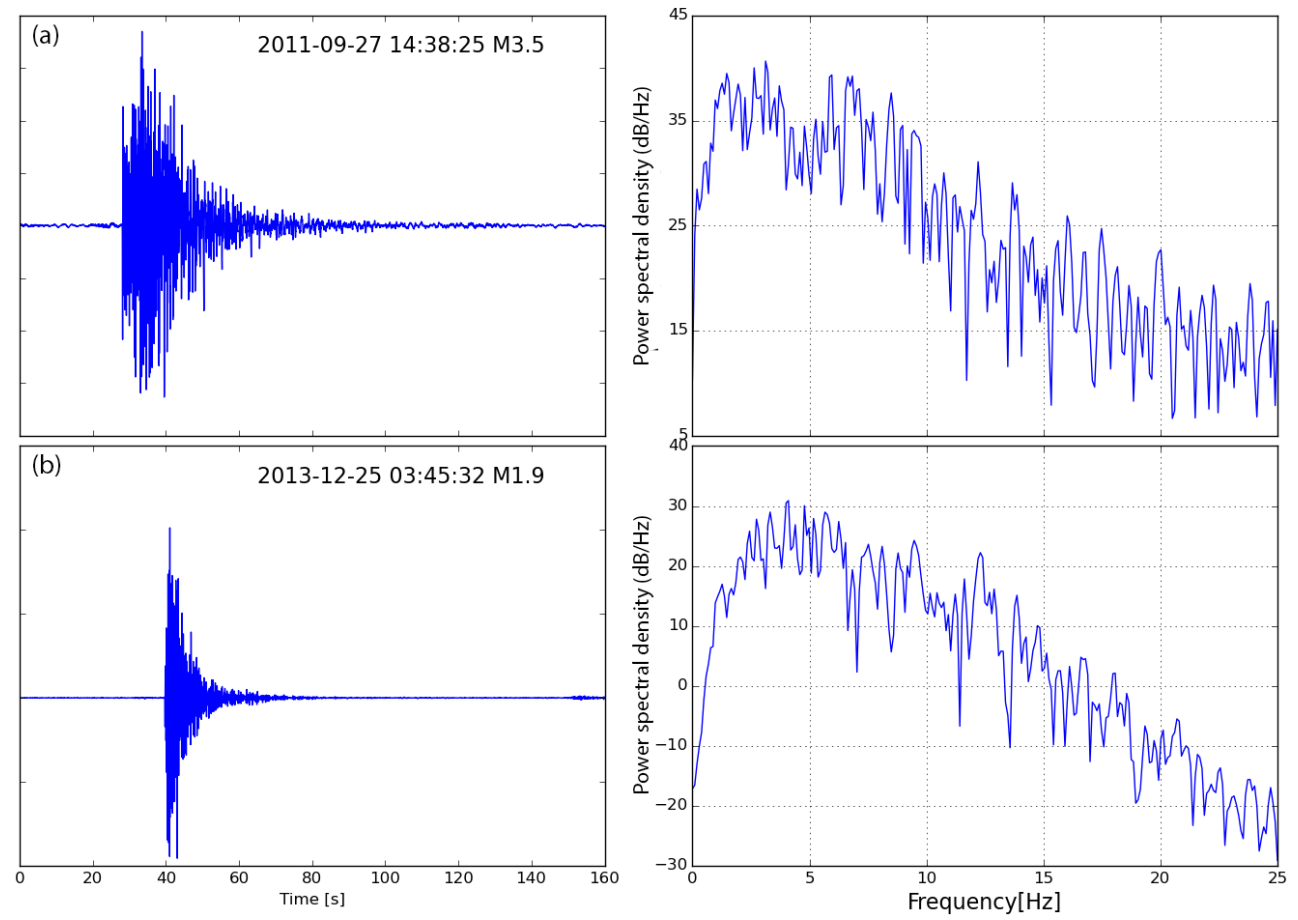

Figure 1. Characteristic VT earthquakes of the El Hierro seismo-volcanic process and their spectra. (a) Event recorded on 27 September 2011, before the eruption, at $\sim 6.3 \mathrm{~km}$ to the SE of the island centre. (b) Event recorded on 24 December 2013, after the eruption at $\sim 10.4 \mathrm{~km}$ SW of the island centre.

events of damaging magnitudes, it is important to detect the non-random components of the swarm evolution, as it contains factors linking different stages of the process that may allow major VT events to be forecast. We assume that such "causal factors" are related to the nature of the magmatic intrusion process at depth that involves an increasing accumulation of localized stress, which produces the VT earthquake when released. In particular, the magmatic intrusions may produce clustered sources of stress in which pressure increases over relatively short timescales.

We picture the situation at El Hierro as voluminous bodies of dense magma intruding into the mantle under the crust from a deeper magma generation region (Martínez-Arevalo et al., 2013). That magma is dense enough to remain in almost isostatic equilibrium at the base of the crust in a process of magmatic underplating (Leahy et al., 2010). As it evolves under the local conditions at mantle-crust boundary depths, the diffusive assimilation of crustal minerals causes an increase in the magma buoyancy over the timescale of centuries as the assimilation diffusivity is at least 1 order of magnitude higher than the thermal diffusivity (McLeod and Sparks, 1998; Portnyagin et al., 2008). The increasing buoyancy causes additional stresses and deformations in the overlying crust. Such processes may induce a causative evolution of the seismicity, reflected as an increased rate of seismic energy release, and a changing distribution in the magnitudes of the VT events, as discussed in the following sections. How- ever, at this point, it is important to note that the analysis of such evolution may enable scientists to forecast the occurrence of major VT events on the short-term timescale; nevertheless, in some cases this analysis may not foretell the occurrence of an eruption, as the magma injection and migration process that causes the stress concentration may never reach the surface (Bell and Kilburn, 2012), although an increase in the probability of such an event must be considered. Next we present this methodology, developed and used during the El Hierro volcanic process (2011-2015), which is aimed at detecting the precursory behaviour of the seismicity before the occurrence of major, potentially damaging VT earthquakes.

\section{El Hierro volcanic process}

The morphology of El Hierro island $\left(27.7^{\circ} \mathrm{N} ; 18.0^{\circ} \mathrm{W}\right)$ has been attributed to a triple volcanic rift with the $\mathrm{NE}, \mathrm{NW}$, and $\mathrm{S}$ axes of these rifts diverging by about $120^{\circ}$ from each other (Carracedo et al., 1999). The island landscape displays abundant dikes and fissures (Gee et al., 2001), as well as major landslides (Masson et al., 2002). The subaerial island displays a high concentration of volcanoes with a spatial distribution that may be explained by the model proposed by Stroncik et al. (2009), in which the volcanic activity at El Hierro is controlled by a complex array of magma pockets. Magma injections from the pockets through dikes or sills may generate VT seismicity. In July 2011, a sudden in- 


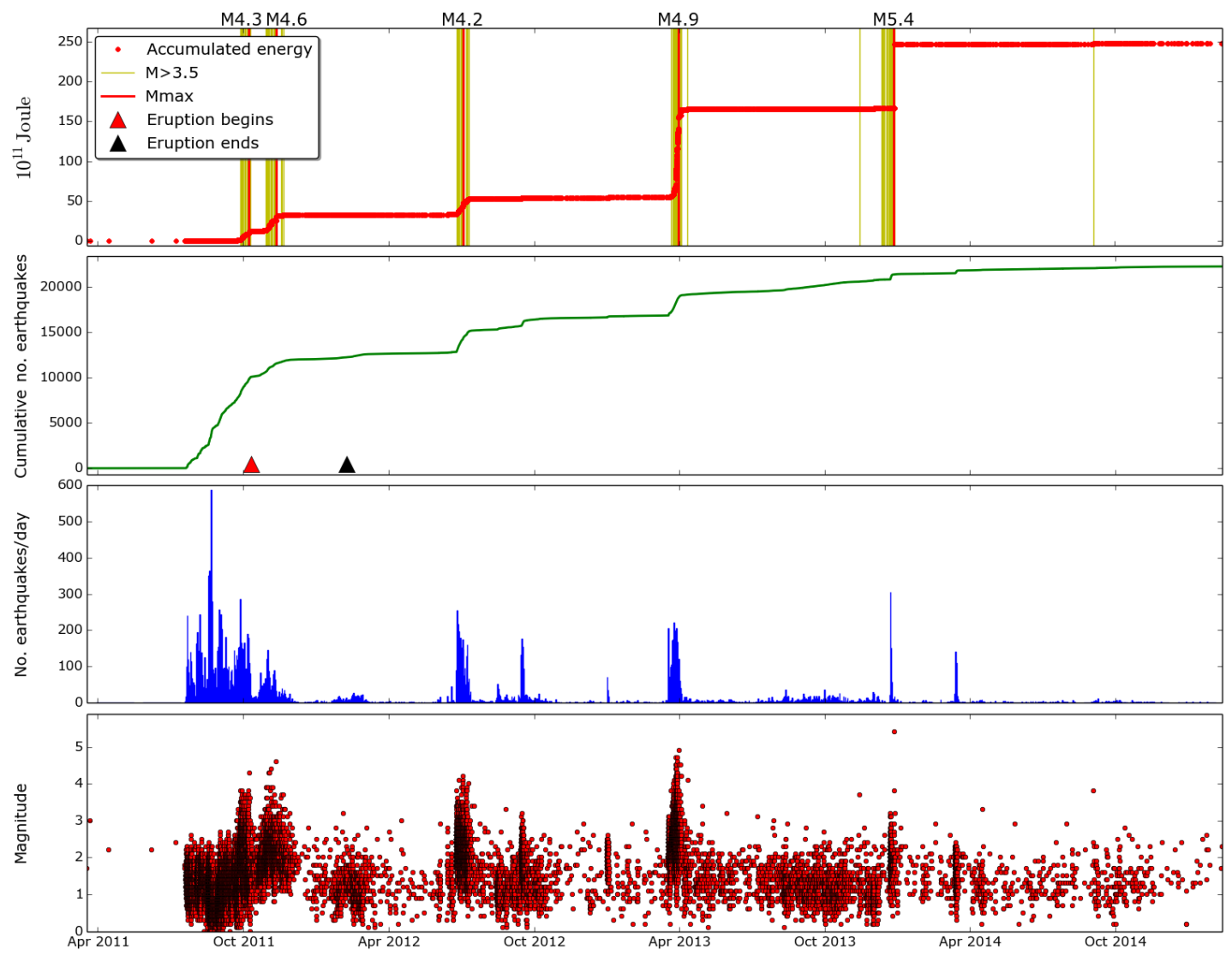

Figure 2. Evolution of the seismic activity at El Hierro island between 18 March 2011 and 12 February 2015. Data are from the IGN public earthquake catalogue and the IGEO-CSIC seismic research network.

crease of seismicity was detected at El Hierro island, prompting several Spanish institutions to deploy recording instrumentation. In addition to the official seismic network operated by the Instituto Geográfico Nacional (IGN), in September 2011, the IGEO-CSIC Institute (see authors' affiliations) installed, for research purposes, a seismic network consisting of three permanent, real-time, vertical, short-period stations, and five similar, temporary, manual-access stations. Seismicity, deformations and diffuse gas emissions increased persistently until October 2011, when a submarine eruption at $27^{\circ} 37.18^{\prime} \mathrm{N} ; 17^{\circ} 59.58^{\prime} \mathrm{W}$ was first detected (López et al., 2012; Ibáñez et al., 2012; Prates et al., 2013). The eruptive activity persisted for months, until March 2012. However, neither the seismic activity nor the deformations stopped, and have in fact continued to the time of this submission (García et al., 2014b, a).

During the whole episode (2011-2015), only two types of seismicity have been observed: short-period volcano-tectonic (VT) earthquakes, with well-defined P and S phases, and a syn-eruptive long-period tremor, patently related to the submarine magma effusion. No long-period (LP) earthquakes have been observed at any time. Here, we analyse the time evolution of the VT earthquakes occurrence rates, as they seem to have similar origins, related to rapid stress concentrations caused by magma intrusions. The VT events do not show significant changes in their waveforms or spectral contents along the duration of the whole episode, as illustrated in Fig. 1.

The evolution of the seismic activity at El Hierro island for the whole period of unrest (2011-2015) is summarized in Fig. 2, in terms of the time distribution of earthquake magnitudes, the number of earthquakes exceeding M1.5 per day, the cumulative number of events, and the cumulative seismic energy released, estimated from the IGN public earthquake catalogue (http://www.ign.es/ign/layoutIn/ sismoFormularioCatalogo.do as downloaded on $29 \mathrm{Au}-$ gust 2015), and from records of the above-mentioned IGEOCSIC seismic research network. The uncertainties in calculating the duration and magnitude of very low-amplitude signals recorded by the IGEO-CSIC have been treated according to Del Pezzo et al. (2003).

Inspection of Fig. 2 reveals that the seismicity, deformations, and eruption evolution observed during the 2011 unrest episode not only are consistent with the model of Stroncik et al. (2009) (García et al., 2014b), but also reveal some other interesting features of the volcanic unrest process 


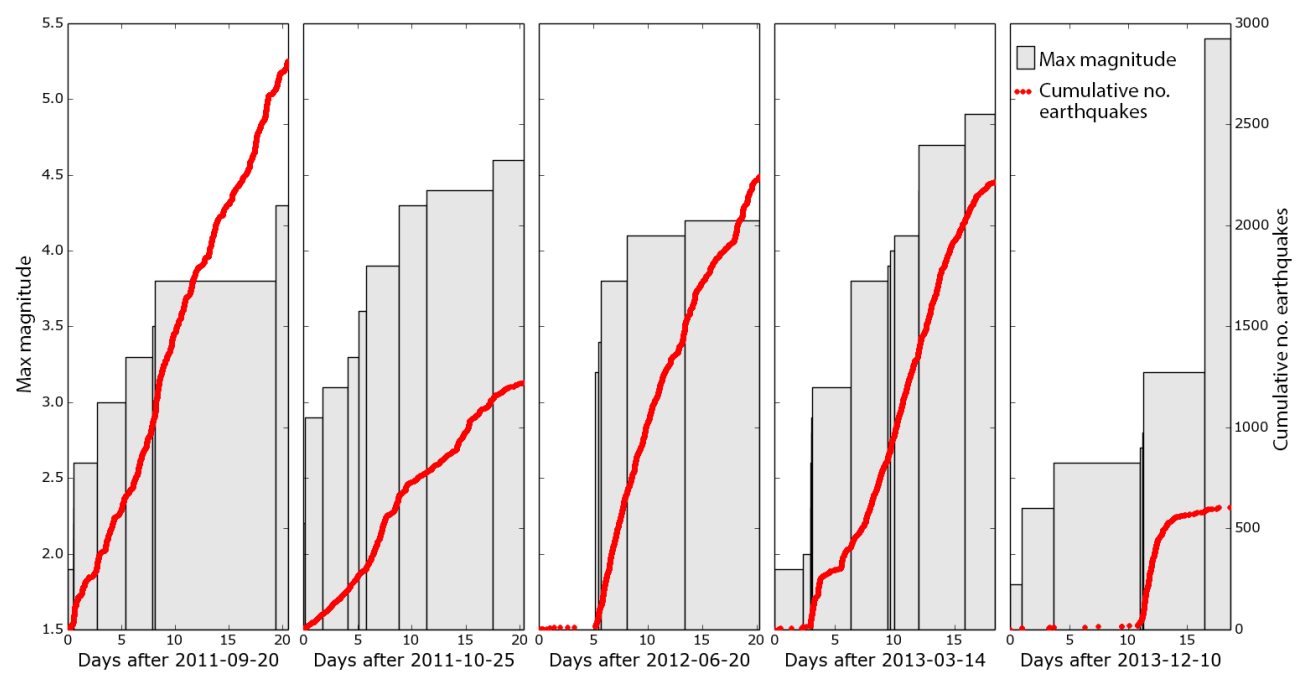

Figure 3. Time evolution of the daily count of VT events (red dots) and maximum magnitudes (gray bars) during the earthquake swarms of the El Hierro seismo-volcanic process.

dynamics. First, as expected, a marked rise of the VT event occurrence rate preceded the onset of the 10 October 2011 eruption. However, during the continuing seismic unrest, the event rate and the cumulative number of events have also markedly increased before the occurrence of major VT earthquakes; but it is the cumulative release of seismic energy, shown in the uppermost plot of Fig. 2, that is the parameter that best illustrates the precursory character before major VT events. Additionally, the $M-T$ diagram in the lower plot of Fig. 2 shows a peculiar behaviour. The minimum magnitude rises as the number of higher-magnitude events increases. This may be caused by completeness fluctuations of the catalogue, derived from the difficulties in counting very small events when larger earthquakes are concurrent, or it may be an actual condition related to the physical process of seismic energy release. Several other cases in which the completeness is maintained at the lowest measurable value during the duration of the VT swarm suggest that the latter condition may be real. For example, Benoit and McNutt (1996) report an increase of the minimum magnitude when the VT activity approaches a mean magnitude of 3 . Likewise, De la CruzReyna et al. (2008) and Hurst et al. (2014) report a similar behaviour for the VT seismicity of Popocatépetl and Tongariro volcanoes respectively.

To date, five seismo-volcanic crises or VT earthquake swarms have been identified at El Hierro (García et al., 2014b, a), showing an increasing trend of the maximum detected magnitudes in all cases, as shown in Fig. 3. It is significant that the acceleration of the seismic energy release rate begins in all cases when the cumulative seismic energy exceeds the $10^{11} \mathrm{~J}$ energy threshold criterion of Yokoyama (1988). Hours to days after the onset of this acceleration stage, the swarm sequences culminated with earthquakes exceeding a magnitude of 4 (Fig. 4). Currently, VT earthquake swarms are classified according to three family types proposed by Benoit and McNutt (1996), and later updated by Farrell et al. (2009) and Brumbaugh et al. (2014): type A mainshock and aftershocks; type B - foreshocks, mainshock, and aftershocks; and type $\mathrm{C}$ - swarms without a mainshock. Further examination of the lower part of Fig. 3 reveals that the evolution of the daily rate of seismicity does not correspond to any of these established earthquake families. We thus introduce a fourth family, type D, characterized by an increasing number of growing magnitude foreshock events culminating with a mainshock and followed by a rapid decay of seismicity lasting just a few hours. The differences between these models are illustrated in Fig. 5. Therefore, a type D sequence does not follow an ETAS model (Ogata, 1992), nor does it follow the Omori law (Utsu and Ogata, 1995), but it reveals a causal process that allows major VT events to be forecast.

\section{Forecasting major VT earthquakes at El Hierro}

The Gutenberg-Richter law (GRL, Gutenberg and Richter, 1944) scales the seismic activity, with respect to its magnitude, as

$\log _{10}(N(M))=a-b M$,

where $N(M)$ is the number of earthquakes with magnitude $M$ or larger detected within a given region, in a certain time interval (Bender, 1983). In a process that remains stationary over a time interval $\Delta T$, the Gutenberg-Richter parameters (GRP) $a$ and $b$ remain constant. Here, we use a timedependent GRP to estimate the mean recurrence time (MRT) of volcanic earthquakes having or exceeding given magnitudes, and thus the likelihood of major events occurring on 


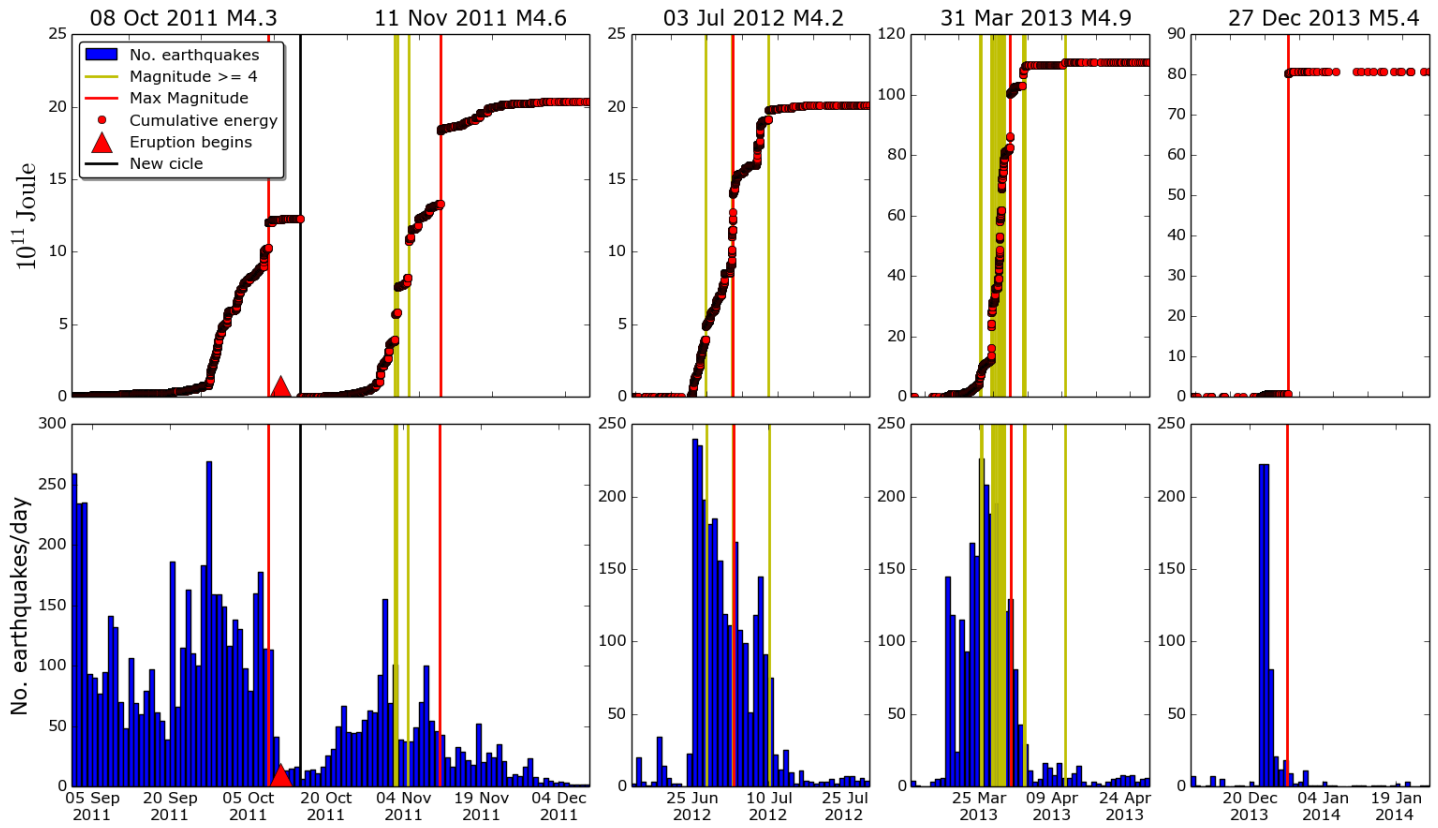

Figure 4. Seismo-volcanic crises identified at El Hierro island (2011-2014). The upper plots show the evolution of seismic energy for each of the cycles of unrest. The lower plots show the daily event count. The plots illustrate how the seismic activity drops rapidly after the largest magnitude earthquakes. Particularly significant is the absence of aftershocks after the largest (M5.4) earthquake of 27 December 2013. Data are from IGN public earthquake catalogue and the IGEO-CSIC seismic research network.
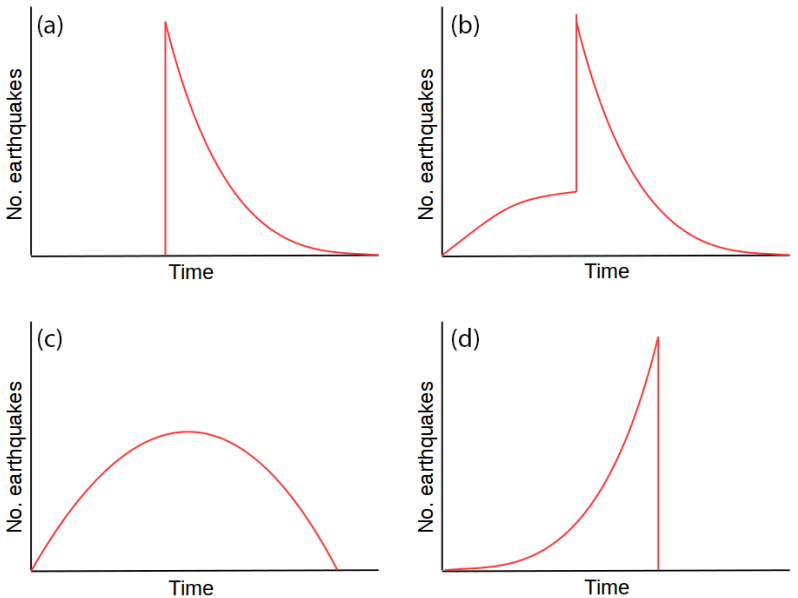

Figure 5. Seismic swarms are usually classified in three family types (A - panel a, B - panel b, C - panel c, Farrell et al., 2009; Brumbaugh et al., 2014). From our results at El Hierro in 20112015, we propose a fourth family type D (panel d), characterized by an increasing number of VT earthquakes and their magnitudes with time, and by a quick decay of the seismicity, in a matter of hours after a mainshock usually exceeding M4.

the shorter timescale (hours to days). The MRT $\left(\tau_{T}\right)$ between events with magnitude equal to or greater than $M$ may thus be estimated from Eq. (1) as

$N(M)=\frac{\Delta T}{\tau_{T}}=10^{(a-b M)}$.
The MRT may thus be calculated as

$\tau_{T}=\Delta T \times 10^{(b M-a)}$.

Increasing likelihood of major events may thus be estimated from the increasing rates of occurrence of smaller earthquakes. In practice this may prove to be a difficult task since the available seismic catalogues frequently present completeness uncertainties derived from technical factors such as the stability of the seismic networks and links, weather conditions, background noise, event counting, and magnitude assignment routines, among others. Problems of catalogue completeness in general mean an undercounting of the lowest magnitudes (Bell and Kilburn, 2012) that define a lowend magnitude cutoff (MC) above which the GRL holds. A second major problem is the bias introduced by the use of binned magnitudes and errors of the magnitudes (Bender, 1983; Tinti and Mulargia, 1985, 1987; Marzocchi and Sandri, 2003). These problems have been amply discussed in the literature about seismicity from different origins (e.g. Wiemer et al., 1998; Lombardi, 2003; Marzocchi and Sandri, 2003; Helmstetter et al., 2007; Amorese et al., 2010; BengoubouValerius and Gibert, 2013; Alamilla et al., 2015; MárquezRamírez et al., 2015). In our case, an additional problem is that the development of the VT seismicity in the El Hierro crisis shows strong and rapid variations, and the estimates for the MC and the GRP may vary in time and space, causing temporary distributions of shocks quite different from those of the full catalogue. We have addressed these prob- 
Table 1. Characteristics of El Hierro swarms.

\begin{tabular}{lrrrr}
\hline $\begin{array}{l}\text { Mainshock } \\
\text { date }\end{array}$ & \multicolumn{2}{c}{ Magnitude } & $\begin{array}{r}\text { Swarm duration } \\
\text { (days) }\end{array}$ & $\begin{array}{r}\text { Number of } \\
\text { events }\end{array}$ \\
\cline { 2 - 3 } & Mean & Max & & \\
\hline 8 Oct 2011 & 2.33 & 4.3 & 10 & 934 \\
11 Nov 2011 & 2.27 & 4.6 & 5 & 354 \\
3 Jul 2012 & 2.35 & 4.2 & 5 & 635 \\
31 Mar 2013 & 2.75 & 4.9 & 4 & 651 \\
27 Dec 2013 & 2.09 & 5.4 & 4 & 466 \\
\hline
\end{tabular}

lems considering a moving and variable time window $\Delta T$ in Eqs. (2) and (3). In most cases, an acceleration of the seismicity occurs when the cumulative energy released by a VT swarm reaches a value near the $10^{11} \mathrm{~J}$ energy threshold of Yokoyama (1988). Experience has shown that at El Hierro such swarms precede a stage of accelerated seismicity with increasing magnitudes that culminate in major $(M>4) \mathrm{VT}$ events.

The MRT algorithm starts a forecast when a swarm of at least 200 earthquakes with $M \geq 1.5$ are detected in a time span of 5 days. Then, a completeness magnitude MC is calculated using the maximum curvature method (MCM, Wiemer and Wyss, 2000). The GRP are estimated for each time window using a maximum likelihood estimator (MLE) (Peishan et al., 2003; Bengoubou-Valerius and Gibert, 2013). In the final standard-C version of the software, we implemented a fast subroutine based on the equations of Marzocchi and Sandri (2003) to calculate the $b$ value:

$b=\frac{1}{\ln (10) \Delta M} \ln (p)$,

where

$$
p=1+\frac{\Delta M}{\mu-M_{\mathrm{c}}},
$$

$\mu$ is the sampling average of the magnitudes and $M_{\mathrm{c}}$ is the cut-off (threshold) magnitude. We used a magnitude binning interval $\Delta M=0.1$. If the seismicity rate drops below 200 earthquakes in 5 days, the MRT algorithm would stop running. In successive swarms, some patterns appear as the time to a mainshock approaches: $M_{\mathrm{c}}$ may increase from the initial 1.5 to as much as 3 or more, and the time window shortens. Algorithm 1 shows a schematic description (pseudocode) of the MRT calculation. The algorithm has been implemented in a batch processing mode that is fast and relatively simple to program.

Table 1 shows the main features of the swarms detected at El Hierro, and Fig. 6 shows the evolution of the MRT for the initial four cycles of El Hierro activity. A warning window for the likely occurrence of an earthquake exceeding M4 is issued when the calculated MRT for that magnitude drops below 10 days, and a statement saying that there

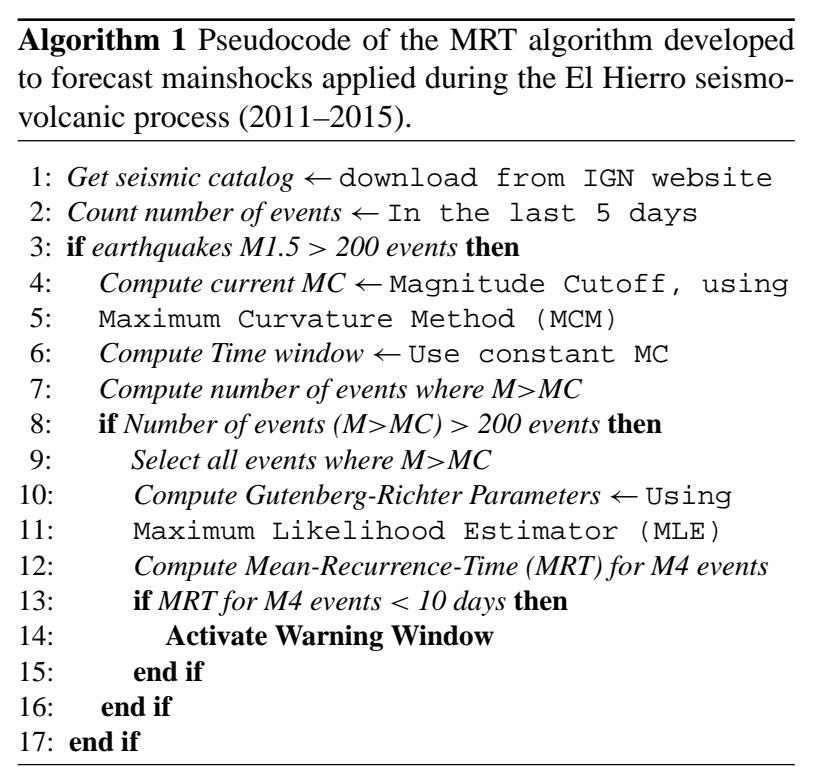

is an increased likelihood of an M4 (or higher) earthquake in the following 10 days is delivered to the decision makers. The warning remains active until the MRT returns to a value exceeding 10 days. This method has been incorporated into a volcanic alert system, (described in García et al., 2014a), where the continuous evolution of the MRT over the whole unrest process is described.

An 8-month lull followed those four cycles, and as frequently happens, a belief that the seismo-volcanic crisis had ended spread throughout the island's population. Additional factors, such as a particularly strong winter storm and the Christmas holidays, caused failures of the IGN official seismic network that translated into a rather incomplete seismic catalogue. When a new seismic swarm began on 20 December 2013, the MRT could only be calculated predominantly using data from the IGEO-CSIC seismic research network. Figure 7 shows the MRT evolution using magnitudes from both catalogues. On 24 December 2013 a new warning was issued communicating to decision makers the increased likelihood of an earthquake M5 or larger occurring in the following days. On 27 December 2013, at 17:46:02 UTC, the largest earthquake of the entire episode, with magnitude 5.4, caused numerous landslides across the island, fortunately without casualties. It is interesting to note that no M4 earthquakes occurred in this stage.

\section{Discussion and conclusions}

Earthquake forecasting is a problem that has been addressed in the past from various different perspectives. Significant advances were obtained after the introduction of complexity theory (Lorenz, 1963; Mandelbrot, 1977) and the development of predictive algorithms (Gabrielov et al., 1986; 

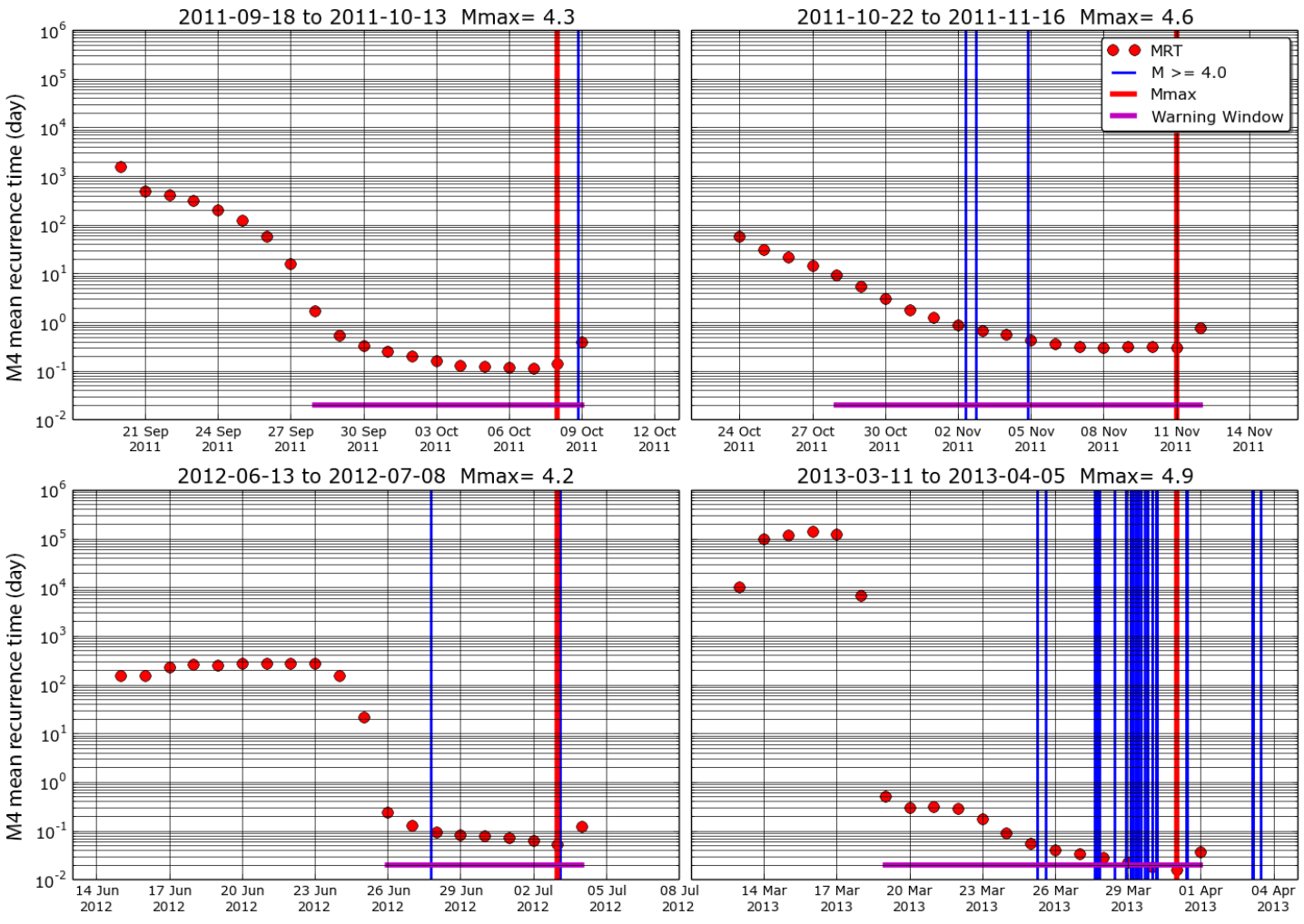

Figure 6. MRT evolution (computed using MLE) for four periods: 18 August 2011 to 10 October 2011; 22 October 2011 to 13 November 2011; 13 June 2012 to 5 July 2012; and 11 March 2013 to 2 April 2013. The warning windows were triggered when MRT dropped below 10 days.

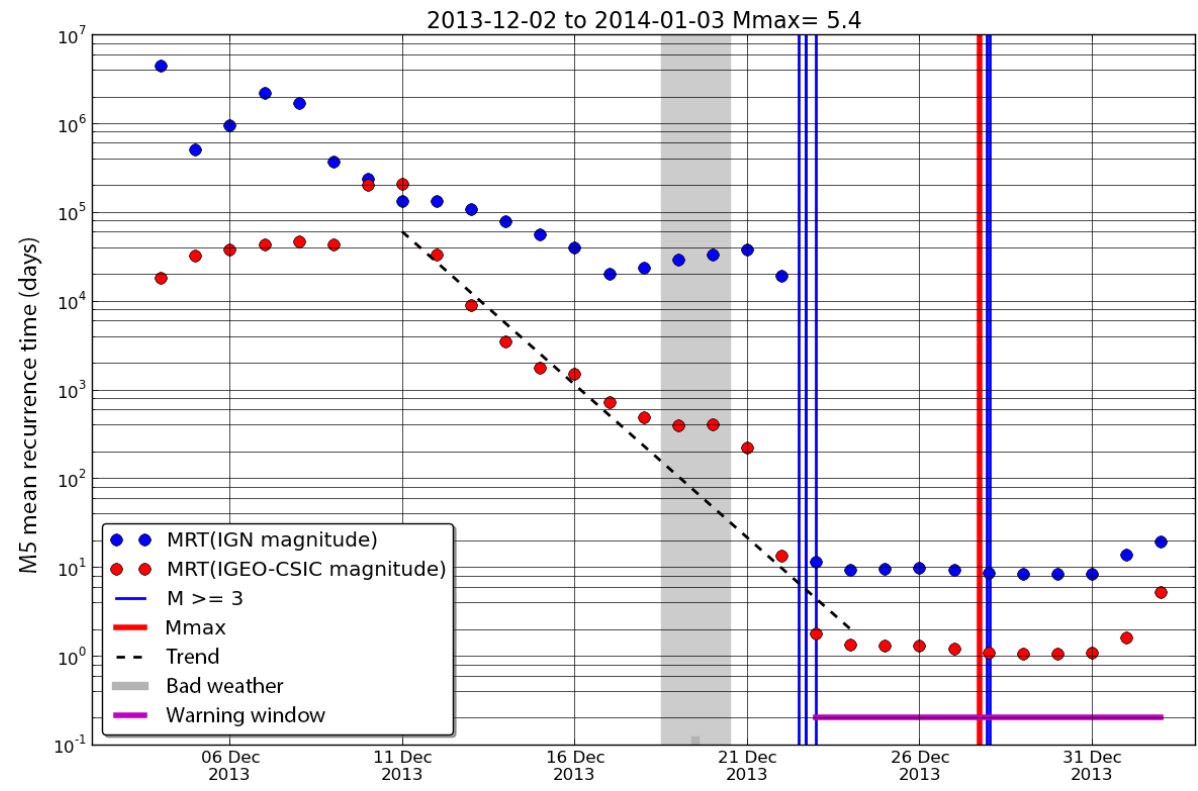

Figure 7. MRT evolution (computed using MLE) in December 2013 calculated from the IGN official catalogue (blue) and from the IGEOCSIC catalogue (red). The magnitude of the earthquake on 27 December 2013 17:46:02 was estimated by IGN as 5.1, and as 5.4 by the IGEO-CSIC network and other international catalogues. 


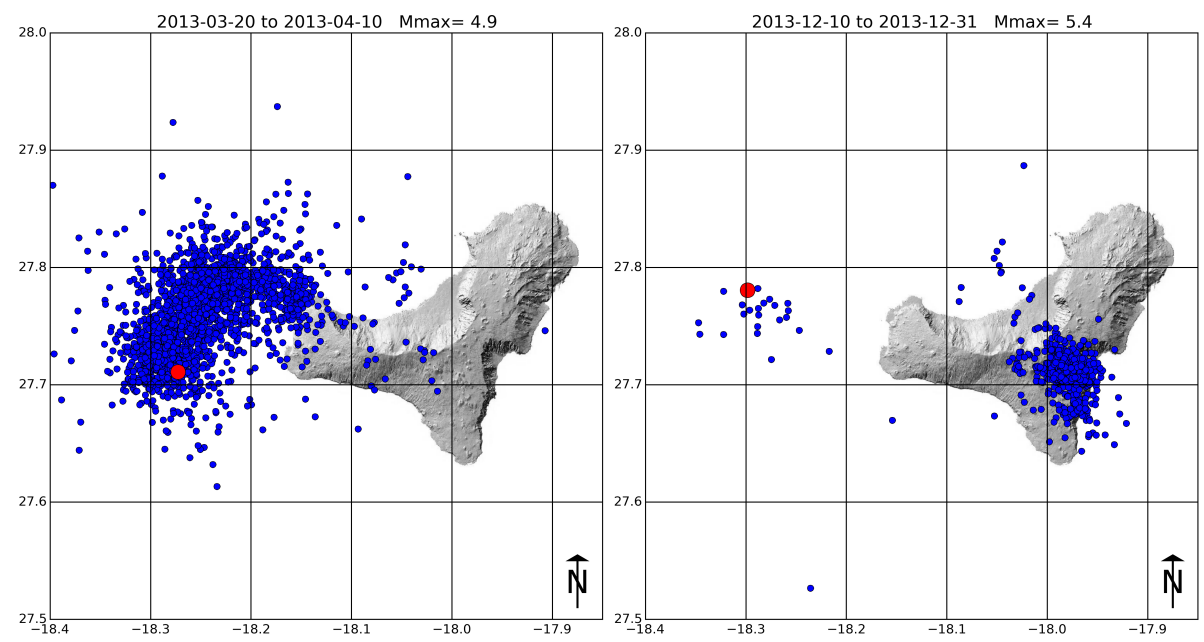

Figure 8. Swarms and mainshock epicentres of the March and December 2013 seismicity cycles. The M5.4 mainshock of 27 December 2013, at 17:46:02 UTC, is located in the same region of the March 2013 cycle.

Molchan, 1990; Keilis-Borok, 1996; Turcotte, 1997). Currently, the need to implement operational short-term earthquake forecasting based on predictive and forecasting algorithms has been stated by Jordan et al. (2011). The MRT is one of such algorithms, based on a property that is typical of complex systems: seismic events cluster according to a simple scaling law, the Gutenberg-Richter relationship (Eq. 1). This empirical relationship contains information about the occurrence of large magnitudes embedded in the number of small-magnitude events (Helmstetter et al., 2007), and the time variations of the distribution of the small-magnitude events provides information about the timescale of largemagnitude occurrences. In the case of VT earthquakes, two additional factors help to simplify the forecasting process: one is the limited geographic extent of the volcanic source of seismicity, confining the spatial extension of the forecast. The other factor is the short timescale, measured in days, at which orderly fluctuations of the GRPs evolve reflecting stress accumulations induced by the magma injections, and allowing rapid recognition of significant changes of the MRT as defined in Eq. (3), and therefore viable short-term forecasts (García et al., 2014a). In contrast, a similar method for tectonic earthquakes would require recognizing orderly evolution patterns of the GRPs over timescales of years to decades, making short-term forecasting non-viable (e.g. Jordan et al., 2011).

We envision the El Hierro process as the result of magma injections causing rapid stress concentrations capable of triggering seismic swarms. Such swarms culminate with mainshocks that release stress concentrations, and are thus not followed by aftershock sequences. Further magma migrations cause new swarms and mainshocks, in repeating, but nonperiodic cycles of activity. For example, the largest earthquakes of the March and December 2013 swarms (see Table 1) were located less than $20 \mathrm{~km}$ west of the western- most shore of the island, suggesting a nearby localized stress source possibly resulting from subsurface magma injections under that region (Fig. 8). From the initial stage of unrest in July 2011, five earthquake swarm cycles have been identified, but only the first of these culminated in an eruption. The subsequent cycles show two main features: first, the swarms are separated by increasingly longer lull intervals, and second, they tend to culminate in mainshocks of increasing magnitudes (see Fig. 3).

The forecasting algorithm we are proposing here is based on the above-mentioned envisioning of the process that is causing the seismic swarms, and begins when the background seismic energy exceeds the $10^{11} \mathrm{~J}$ energy threshold criterion of Yokoyama (1988). The acceleration of the earthquake rate (Fig. 5d) is interpreted in terms of piecewise estimations of the Gutenberg-Richter parameters. The variations of those parameters are, in turn, translated as time windows of increased likelihood of a large-magnitude earthquake. The MRT algorithm may be, and has been, used in real time. It took the initial VT swarm crises to interpret the process and to recognize and develop the procedures and set the parameters of the MRT algorithm, which was first tested during the third crisis, when a significant reduction of the MRT was detected on 5 May 2012. A M4.2 VT earthquake occurred on 3 July 2012. From then on, the MRT algorithm ran continuously in the background. It was not until the fourth crisis that a formal warning was issued on 26 March 2013 communicating to the island authorities and to the Civil Protection officials the increased probability of a M5 earthquake for the following 8 days, as described in García et al. (2014a). On 31 March 2013 a M4.9 earthquake occurred. In the next volcano-tectonic seismic crisis another formal warning was issued on 22 December 2013, communicating the increased probability of an earthquake exceeding M5 in the next 15 days. Further formal warnings were issued daily af- 
terwards also indicating the increased probability of landslides and other eruption. On 27 December 2013, an M5.4 caused numerous landslides (García et al., 2014a).

In the absence of swarms, the GRPs are calculated with a long database of the seismic catalogue, and updated on a daily basis (Algorithm 1), usually yielding fluctuating, but always very long values of the MRT (that may exceed 106 days). At the onset of a seismic swarm, the MRT drops rapidly to values of the order of 103 days. When this happens the GRPs are calculated from shorter time windows of variable duration, provided that they contain a large enough number of events (at least 200) to yield stable values of the GRPs. When the MRT for events of magnitude 4 or higher is less than 10 days, a warning is issued to the decision makers, expressed as a 10-day window of increased likelihood for larger, potentially damaging earthquakes. Up to the time of this submission, all the recent earthquakes of $M \geq 4$ at El Hierro have been forecasted several days in advance. Application of the MRT to other volcanoes may be relatively simple to implement, provided that the observed seismicity corresponds to swarms of type D (Fig. 5): increasing number of VT events with increasing magnitudes followed by a mainshock, and by a rapid decay of the seismicity afterwards. The algorithm may be readily adapted to any real-time monitoring system. In addition, the concept of time windows for the increased likelihood of a large-magnitude earthquake should be easily understood and accepted by governmental decision makers, making the management of risk more effective.

Acknowledgements. This research has been funded by projects from the CSIC (2011-30E070) and MINECO (CGL2011-28682C02-01). The authors are grateful to the DGAPA-PAPIIT-UNAM program for their support. We used seismic data from the IGN public website (http://www.02.ign.es/ign/layout/sismo.do, public website, ${ }^{\circledR}$ Instituto Geográfico Nacional). S. Malone, an anonymous reviewer and the editor, G. Macedonio, provided valuable comments that helped to clarify and strengthen various parts of the manuscript. We are also indebted to the Cabildo Insular de El Hierro, and its three municipalities (Valverde, El Pinar de El Hierro, and Frontera) for their support. We wish to thank all of the people living on El Hierro for their encouragement and understanding of our scientific work.

Edited by: G. Macedonio

Reviewed by: S. D. Malone and one anonymous referee

\section{References}

Alamilla, J. L., Vai, R., and Esteva, L.: Completeness assessment of earthquake catalogues under uncertain knowledge, J. Seismol., 19, 27-40, doi:10.1007/s10950-014-9448-x, 2015.

Amorese, D., Grasso, J.-R., and Rydelek, P. A.: On varying b-values with depth: results from computer-intensive tests for Southern California, Geophys. J. Int., 180, 347-360, doi:10.1111/j.1365246X.2009.04414.x, 2010.
Ancochea, E., Hernán, F., Cendrero, A., Cantagrel, J. M., Fúster, J. M., Ibarrola, E., and Coello, J.: Constructive and destructive episodes in the building of a young Oceanic Island, La Palma, Canary Islands, and genesis of the Caldera de Taburiente, J. Volcanol. Geoth. Res., 60, 243-262, doi:10.1016/03770273(94)90054-X, 1994.

Bell, A. F. and Kilburn, C. R.: Precursors to dyke-fed eruptions at basaltic volcanoes: insights from patterns of volcano-tectonic seismicity at Kilauea volcano, Hawaii, B. Volcanol., 74, 325339, doi:10.1007/s00445-011-0519-3, 2012.

Bender, B.: Maximum likelihood estimation of $b$ values for magnitude grouped data, B. Seismol. Soc. Am., 73, 831-851, 1983.

Bengoubou-Valerius, M. and Gibert, D.: Bootstrap determination of the reliability of b-values: an assessment of statistical estimators with synthetic magnitude series, Nat. Hazards, 65, 443-459, doi:10.1007/s11069-012-0376-1, 2013.

Benoit, J. P. and McNutt, S. R.: Global volcanic earthquake swarm database 1979-1989. Open-file report 96-69, US Department of the Interior, US Gological Survey, 1996.

Brumbaugh, D., Hodge, B., Linville, L., and Cohen, A.: Analysis of the 2009 earthquake swarm near Sunset Crater volcano, Arizona, J. Volcanol. Geoth. Res., 285, 18-28, doi:10.1016/j.jvolgeores.2014.07.016, 2014.

Carracedo, J. C., Day, S. J., Guillou, H., and Pérez-Torrado, F. J.: Giant Quaternary landslides in the evolution of La Palma and El Hierro, Canary Islands, J. Volcanol. Geoth. Res., 94, 169-190, doi:10.1016/S0377-0273(99)00102-X, 1999.

De la Cruz-Reyna, S., Yokoyama, I., Martinez-Bringas, A., and Ramos, E.: Precursory seismicity of the 1994 eruption of Popocatepetl Volcano, Central Mexico, B. Volcanol., 70, 753767, doi:10.1007/s00445-008-0195-0, 2008.

Del Pezzo, E., Bianco, F., and Saccorotti, G.: Duration magnitude uncertainty due to seismic noise: inferences on the temporal pattern of GR b-value at Mt. Vesuvius, Italy, B. Seismol. Soc. Am., 93, 1847-1853, doi:10.1785/0120020222, 2003.

Farrell, J., Husen, S., and Smith, R. B.: Earthquake swarm and b-value characterization of the Yellowstone volcanotectonic system, J. Volcanol. Geoth. Res., 188, 260-276, doi:10.1016/j.jvolgeores.2009.08.008, 2009.

Gabrielov, A., Dmitrieva, O., Keilis-Borok, V., Kossobokov, V., Kutznetsov, I., Levshina, T., Mirzoev, K., Molchan, G., Negmatullaev, S., Pisarenko, V., Prozorov, A., Rinheart, W., Rotwain, I., Shelbalin, P., Shnirman, M., and Schreider, S.: Algorithms of long-term earthquakes' prediction, international school on research oriented to earthquake prediction-algorithms, software and data handling, Centro Regional de Sismología para América del Sur, Lima, Peru, 1986.

García, A., Berrocoso, M., Marrero, J. M., Fernández-Ros, A., Prates, G., De la Cruz-Reyna, S., and Ortiz, R.: Volcanic alert system (VAS) developed during the 2011-2014 El Hierro (Canary Islands) volcanic process, B. Volcanol., 76, 825, doi:10.1007/s00445-014-0825-7, 2014a.

García, A., Fernández-Ros, A., Berrocoso, M., Marrero, J., Prates, G., De la Cruz-Reyna, S., and Ortiz, R.: Magma displacements under insular volcanic fields, applications to eruption forecasting: El Hierro, Canary Islands, 2011-2013, Geophys. J. Int., 196, 1-13, doi:10.1093/gji/ggt505, 2014b. 
Gee, M. J., Watts, A. B., Masson, D. G., and Mitchell, N. C.: Landslides and the evolution of El Hierro in the Canary Islands, Mar. Geol., 177, 271-293, 2001.

Gutenberg, B. and Richter, C. F.: Frequency of earthquakes in California, B. Seismol. Soc. Am., 34, 185-188, 1944.

Helmstetter, A., Kagan, Y. Y., and Jackson, D. D.: Highresolution time-independent grid-based forecast for $\mathrm{M} 5$ earthquakes in California, Seismol. Res. Lett., 78, 78-86, doi:10.1785/gssrl.78.1.78, 2007.

Hurst, T., Jolly, A. D., and Sherburn, S.: Precursory characteristics of the seismicity before the 6 August 2012 eruption of Tongariro volcano, North Island, New Zealand, J. Volcanol. Geoth. Res., 286, 294-302, doi:10.1016/j.jvolgeores.2014.03.004, 2014.

Ibáñez, J. M., De Angelis, S., Díaz-Moreno, A., Hernández, P., Alguacil, G., Posadas, A., and Pérez, N.: Insights into the 2011-2012 submarine eruption off the coast of El Hierro (Canary Islands, Spain) from statistical analyses of earthquake activity, Geophys. J. Int., 191, 659-670, doi:10.1111/j.1365246X.2012.05629.x, 2012.

Jordan, T. H., Chen, Y. T., Gasparini, P., Madariaga, R., Main, I., Marzocchi, W., Papadopoulos, G., Sobolev, G., Yamaoka, K., and Zschau, J.: Operational Earthquake Forecasting. State of Knowledge and Guidelines for Utilization, Ann. Geophys.-Italy 54, 315-391, doi:10.4401/ag-5350, 2011.

Keilis-Borok, V.: Intermediate-term earthquake prediction, P. Natl. Acad. Sci. USA, 93, 3748-3755, 1996.

Leahy, G. M., Collins, J. A., Wolfe, C. J., Laske, G., and Solomon, S. C.: Underplating of the Hawaiian Swell: evidence from teleseismic receiver functions, Geophys. J. Int., 183, 313-329, doi:10.1111/j.1365-246X.2010.04720.x, 2010.

Lombardi, A. M.: The maximum likelihood estimator of bvalue for mainshocks, B. Seismol. Soc. Am., 93, 2082-2088, doi:10.1785/0120020163, 2003.

López, C., Blanco, M. J., Abella, R., Brenes, B., RodríguezCabrera, V. M., Casas, B, Cerdeña, I. D., Felpeto, A., de Villalta, F., del Fresno, C., García, O., García-Arias, M., GarcíaCañada, L., Gomis-Moreno, A., González-Alonso, E., GuzmánPérez, J., Iribarren, I., López-Díaz, R., Luengo-Oroz, N., Meletlidis, S., Moreno, M., Moure, D., Pereda de Pablo, J., Rodero, C., Romero, E., Sainz-Maza, S., Sentre-Domingo, M., Torres, P., Trigo, P., and Villasante-Marcos, V.: Monitoring the volcanic unrest of El Hierro (Canary Islands) before the onset of the 2011-2012 submarine eruption, Geophys. Res. Lett., 39, L13303, doi:10.1029/2012GL051846, 2012.

Lorenz, E. N.: Deterministic nonperiodic flow, J. Atmos. Sci., 20, 130-141, 1963.

Mandelbrot, B. B.: Fractals: Form, Chance and Dimension, W. H. Freeman and Co., San Francisco, 1977.

Márquez-Ramírez, V., Nava, F., and Zúñiga, F.: Correcting the Gutenberg-Richter b-value for effects of rounding and noise, Earthquake Science, 28, 129-134, doi:10.1007/s11589-0150116-1, 2015.

Martínez-Arevalo, C., Mancilla, F. d. L., Helffrich, G., and García, A.: Seismic Evidence of a Regional Sublithospheric Low Velocity Layer beneath the Canary Islands, Tectonophysics, 608, 586599, doi:10.1016/j.tecto.2013.08.021, 2013.
Marzocchi, W. and Sandri, L.: A review and new insights on the estimation of the b-value and its uncertainty, Ann. Geophys.-Italy, 46, 1271-1282, 2003.

Masson, D., Watts, A., Gee, M., Urgeles, R., Mitchell, N., Bas, T. L., and Canals, M.: Slope failures on the flanks of the western Canary Islands, Earth-Sci. Rev., 57, 1-35, 2002.

McLeod, P. and Sparks, R. S. J.: The dynamics of xenolith assimilation, Contrib. Mineral. Petr., 132, 21-33, doi:10.1007/s004100050402, 1998.

Molchan, G.: Strategies in strong earthquake prediction, Phys. Earth Planet. In., 61, 84-98, doi:10.1016/0031-9201(90)90097H, 1990.

Ogata, Y.: Detection of precursory relative quiescence before great earthquakes through a statistical model, J. Geophys. Res.-Sol. Ea., 97, 19845-19871, doi:10.1029/92JB00708, 1992.

Peishan, C., Tongxia, B., and Baokun, L.: The b-Value and Earthquake Occurrence Period, Chinese J. Geophys., 46, 736-749, doi:10.1002/cjg2.3393, 2003.

Portnyagin, M., Almeev, R., Matveev, S., and Holtz, F.: Experimental evidence for rapid water exchange between melt inclusions in olivine and host magma, Earth Planet. Sc. Lett., 272, 541-552, doi:10.1016/j.eps1.2008.05.020, 2008.

Prates, G., García, A., Fernández-Ros, A., Marrero, J. M., Ortiz, R., and Berrocoso, M.: Enhancement of sub-daily positioning solutions for surface deformation surveillance at El Hierro volcano (Canary Islands - Spain), B. Volcanol., 75, 724, doi:10.1007/s00445-013-0724-3, 2013.

Stroncik, N., Klügel, A., and Hansteen, T.: The magmatic plumbing system beneath El Hierro (Canary Islands): constraints from phenocrysts and naturally quenched basaltic glasses in submarine rocks, Contrib. Mineral. Petr., 157, 593-607, doi:10.1007/s00410-008-0354-5, 2009.

Tinti, S. and Mulargia, F.: Effects of magnitude uncertainties on estimating the parameters in the Gutenberg-Richter frequencymagnitude law, B. Seismol. Soc. Am., 75, 1681-1697, 1985.

Tinti, S. and Mulargia, F.: Confidence intervals of b-values for grouped magnitudes, B. Seismol. Soc. Am., 77, 2125-2134, 1987.

Turcotte, D. L.: Fractals and chaos in geology and geophysics, Cambridge University Press, 1997.

Utsu, T. and Ogata, Y.: The centenary of the Omori formula for a decay law of aftershock activity, J. Phys. Earth, 43, 1-33, 1995.

Wiemer, S. and Wyss, M.: Minimum magnitude of completeness in earthquake catalogs: examples from Alaska, the western United States, and Japan, B. Seismol. Soc. Am., 90, 859-869, doi:10.1785/0119990114, 2000.

Wiemer, S., McNutt, S. R., and Wyss, M.: Temporal and threedimensional spatial analyses of the frequency-magnitude distribution near Long Valley Caldera, California, Geophys. J. Int., 134, 409-421, doi:10.1046/j.1365-246x.1998.00561.x, 1998.

Yokoyama, I.: Seismic energy releases from volcanoes, B. Volcanol., 50, 1-13, doi:10.1007/BF01047504, 1988.

Zobin, V. M.: Seismic hazard of volcanic activity, J Volcanol. Geoth. Res., 112, 1-14, doi:10.1016/S0377-0273(01)00230-X, 2001. 